\title{
The Czech version of the Utian Quality of Life Scale questionnaire assessing women's quality of life during menopause
}

\author{
Marketa Moravcova ${ }^{1}$, Jiri Mares ${ }^{2}$, Katerina Horackova ${ }^{1}$ \\ ${ }^{1}$ Faculty of Health Studies, University of Pardubice, Czech Republic \\ ${ }^{2}$ Faculty of Medicine in Hradec Kralove, Charles University in Prague, Czech Republic
}

\begin{abstract}
Introduction: Menopause is a physiological process, forming a part of a lifetime that most women go through. This period of life is briefly described by experts as a triple transformation: biological, social, and psychological. For menopausal women, health care professionals can use one of 10 specific questionnaires to assess health-related quality of life and its symptoms. The authors herein speak about the preparation of a Czech version of one such questionnaire - the Utian Quality of Life Scale (UQOL).

Material and methods: A Czech version of the UQOL was created by repeated and backward translation. It was validated on a sample of 204 women after natural menopause (45-65 years old). We judged the reliability of the Czech version of UQOL using Cronbach's $\alpha$. We assessed the instrument's validity by means of confirmation factor analysis.

Results: The authors modified the original version of the UQOL. The Czech version has 4 new domains with 18 items. This form was created using the results of confirmation factor analysis.

Conclusions: The Utian Quality of Life Scale questionnaire is completed by the women themselves, thus meeting the golden rule of all quality-of-life research stating that the primary source should be data from the client him/herself. However, this requirement raises some methodological problems.
\end{abstract}

Key words: assessing, menopause, quality of life, Utian Quality of Life Scale.

\section{Introduction}

Menopause is a physiological process, forming a part of a lifetime that most women go through. This period is briefly described by experts as a triple transformation: biological, social, and psychological. Biological changes in a woman's body are related to a decrease in oestrogen levels and, to a varying extent, to a developing oestrogen deficiency. From a clinical perspective, menopause is defined as a permanent menstrual arrest due to loss of ovarian follicular function, retrospectively evaluable after 12 months of amenorrhoea [1]. From a social point of view, this period is marked by changes that woman often cannot influence: her parents are ageing and need her care, her children have grown up and left home, and the woman's life and work perspectives change. From a psychological perspective, the woman is increasingly concerned with her health and possible sickness, decreasing physical attractiveness and performance, and finally with the subject of her own mortality. In this period, women often complain about future-related concerns, unattainability of further life goals, uncertainty, and depressive conditions. The mean age of menopause in our research group was between 49 and 51 years [2]. Given the actual demographic situation of the Czech population, menopause is not a question of a small group of women, but of hundreds of thousands of persons.

Current clinical practice provides menopausal women with health care, consisting of care provided by a general practitioner, a gynaecologist, a midwife (general nurse), and other specialists, depending on the nature of the problems present. Symptoms of oestrogen deficiency can be divided into acute (climacteric syndrome), subacute (organic oestrogen deficiency syndrome), and chronic (metabolic oestrogen deficiency syndrome). Numerous menopause manifestations are new to women, surprising them with their course as well as their intensity and frequency. Acute problems usually do not endanger a woman's health but reduce her quality of life, complicating the performance of her daily activities. Subacute and chronic symptoms may be severe and may worsen a woman's health condition. However, women usually come to the gynaecological outpatient clinic only with present symptoms of oestrogen deficiency and not in a phase of relief. At the same time, early diagnosis and targeted prevention of 
certain oestrogen deficiency symptoms is the most effective solution to possible complications in the period affected by menopause.

The most effective and comprehensive therapy of several oestrogen deficiency symptoms is hormone replacement therapy. The range of preparations applicable as an alternative of hormone replacement therapy is also expanding. These are substances with a complex effect on menopausal symptoms (e.g. tibolone). The treatment also utilizes substances correcting isolated menopausal symptoms: intrauterine hormone system with levonorgestrel for treating uterine bleeding, biophosphonates for treating bone loss, phytohormones, etc. In addition, psychotherapeutic care is necessary in some cases to help the woman reassess her value system and to find an altered, new meaning of life [3].

While the clinical impact of menopause and the related oestrogen deficiency are described in many respects in expert literature, the description of the impact of this period on women's psychological well-being, their menopause experience, and quality of life is somewhat lagging. Some foreign studies have shown that the quality of life of some women is significantly decreasing in the menopause period [4-7].

\section{Assessing women's quality of life in the period affected by menopause}

In recent decades, quality of life as a general term has been used in many fields of science, ranging from medical to social to technical sciences. The healthcare generally defines the quality of life in the context of health and illness, while the number of practical applications is constantly rising. Nowadays medical and nursing care include considerations not only on saving or prolonging human life, but also on the quality of the months and years added to human life.

"Quality of life" as a category generally applied in healthcare and in the various medical fields (including gynaecology and obstetrics) has its specific designation health-related quality of life (HRQL). However, there is no unity in the theoretical definition of this term. Theoretician [8] therefore advocates the definition proposed by the US Centre for Disease Prevention and Treatment. This definition is as follows: HRQL comprises those aspects of overall quality of life that can be clearly shown to be affected by health, whether somatic or mental. It can be described as perceived somatic and mental health, including the context of the type of health risks and conditions, functional status, social support, and socio-economic status. At the community level, HRQL includes resources, conditions, health policy, and practices affecting the population's perceived health and functional status (modified concept by 9 ).

Thus, the quality of life is a multi-level, dynamic, and unfortunately - as described e.g. by [10] - an amorphous category. It is therefore necessary (for both theoretical and practical reasons) to split up the general category of HRQL to more subtle elements and to distinguish its individual aspects. Usually we talk about various areas, domains of quality of life, facilitating the diagnosis of quality of life.

For our further explication, it is important that the quality of human life is understood as a matter of subjective, not objective data. It clearly depends on the individual's personal perception, experience, and assessment of the various areas of quality of life, not on how they objectively are, i.e. how they appear to external observers.

In the introduction we mentioned that in the period affected by menopause women may experience health, social, and psychological issues. It is therefore important for both physicians and midwives to identify the problems currently experienced by a given woman, how severe they are, how they change over time, and how they respond to potential therapy. This is enabled by methods of assessing quality of life related to the somatic and mental health of individuals. Generally, there are 3 types of methods available to health professionals. Generic - allowing assessment of the quality of life of both healthy and ill people and, for ill persons, the quality of life regardless of a particular disease (thus allowing a comparison of healthy and ill persons as well as a comparison of patients with various diseases). Specific - focusing on a specific illness and assessing the quality of life of a patient affected by the given disease. And finally, combined methods - merging both approaches.

For menopausal women, health professionals can use one of 10 specific questionnaires. Their brief overview is shown in Table 1.

At present, only the Czech version of the Menopause Rating Scale questionnaire (MRS) [23] is available to our expert public. It was created with the consent of the original version's authors, and it is currently starting to be applied in clinical practice [24]. According to Gawlicki [25], a Czech language version of the Green Glimacteric Scale [14] has also been created. However, according to available sources, it is not curently routinely used in Czech clinical practice.

The objective of the present study is to give the readers an idea of the Czech version of another questionnaire, enabling us to determine quality of a woman's life in the menopausal period - the Utian Quality of Life Scale (UQOL).

\section{Original version of the Utian Quality of Life Scale questionnaire}

The shape of Utian's form has evolved from the early 1970s to the present day. The questionnaire was originally designed to assess the feeling of well-being of patients in a clinical study comparing the effective- 
ness of oestrogen therapy with placebo [26]. The researchers' main objective was to create a specific tool that would enable women in the perimenopausal and postmenopausal periods to measure changes in quality of life over time. It was supposed to be a tool that could be used in everyday clinical practice and be comprehensible for women who complete it, timesaving, reliable, valid, and rapidly evaluated.

The basic shape of the instrument was created at the Case Western Reserve University in Cleveland, USA. Experienced researchers proposed an extensive initial set of possible questionnaire items and discussed it in a focus group of 8 women. A draft version of the questionnaire was created by reducing the original version to comprise 40 items; each item assessed using a 5-degree scale. The draft version was administered to 327 women aged 45 to 65 years. The research group consisted of women treated both in obstetrics and gynaecological outpatient clinics and in obstetrics and gynaecological clinics of hospitals in the American East and Midwest. Geographically, the area of concern consisted of 12 urban and suburban localities.

Table 1. Specific questionnaires for assessing the quality of life of women in the period affected by menopause [11-22]

\begin{tabular}{|c|c|c|c|c|c|}
\hline Questionnaire title & Author(s) & Country & $\begin{array}{l}\text { Number } \\
\text { of items }\end{array}$ & Responding method & $\begin{array}{l}\text { Number of domains } \\
\text { and their designation }\end{array}$ \\
\hline Cervantes Scale & $\begin{array}{l}\text { Palacios et al. } \\
\qquad(2002)\end{array}$ & Spain & 31 & Six-degree scale & $\begin{array}{l}\text { 1. Menopause and health } \\
\text { 2. Sexuality } \\
\text { 3. Partner relationship } \\
\text { 4. Psychological }\end{array}$ \\
\hline $\begin{array}{l}\text { Green Climacteric } \\
\text { Scale }\end{array}$ & Green (1998) & UK & 21 & Four-degree scale & $\begin{array}{l}\text { 1. Psychological } \\
\text { 2. Somatic } \\
\text { 3. Vasomotor }\end{array}$ \\
\hline $\begin{array}{l}\text { Menopause } \\
\text { Representations } \\
\text { Questionnaire }\end{array}$ & $\begin{array}{c}\text { Hunter (2000) } \\
\text { Hunter, Rendall } \\
(2007)\end{array}$ & UK & 37 & Five-degree scale & $\begin{array}{l}\text { 1. Menopausal symptoms } \\
\text { 2. Psychological } \\
\text { 3. Risky behaviour }\end{array}$ \\
\hline $\begin{array}{l}\text { Menopause Quality } \\
\text { of Life Scale }\end{array}$ & $\begin{array}{l}\text { Jacobs et al. } \\
(2000)\end{array}$ & UK & 48 & Six-degree scale & $\begin{array}{l}\text { 1. Energy } \\
\text { 2. Sleep } \\
\text { 3. Appetite } \\
\text { 4. Cognitive area } \\
\text { 5. Feelings } \\
\text { 6. Human interaction } \\
\text { 7. Symptoms }\end{array}$ \\
\hline $\begin{array}{l}\text { Menopause Rating } \\
\text { Scale }\end{array}$ & $\begin{array}{c}\text { Heinemann, } \\
\text { Schneider (2004) }\end{array}$ & Germany & 11 & Five-degree scale & $\begin{array}{l}\text { 1. Psychological } \\
\text { 2. Somato-vegetative } \\
\text { 3. Urogenital }\end{array}$ \\
\hline $\begin{array}{l}\text { Menopause-Specific } \\
\text { Quality of Life } \\
\text { Questionnaire }\end{array}$ & Hilditch (1996) & Canada & $\begin{array}{l}29 \\
32\end{array}$ & Seven-degree scale & $\begin{array}{l}\text { 1. Somatic } \\
\text { 2. Vasomotor } \\
\text { 3. Psychological } \\
\text { 4. Sexual } \\
\text { 5. General items for quality of life }\end{array}$ \\
\hline $\begin{array}{l}\text { Menopause } \\
\text { Symptoms List }\end{array}$ & Perz (1997) & Australia & 25 & Six-degree scale & $\begin{array}{l}\text { 1. Psychological } \\
\text { 2. Vasomotor } \\
\text { 3. Generally somatic }\end{array}$ \\
\hline Qualifemme & Le Floch (1994) & France & 26 & $\begin{array}{c}10 \mathrm{~mm} \text { visual } \\
\text { analogue scale }\end{array}$ & $\begin{array}{l}\text { 1. General } \\
\text { 2. Psychological } \\
\text { 3. Vasomotor } \\
\text { 4. Urogenital } \\
\text { 5. Pain, skin, hair }\end{array}$ \\
\hline $\begin{array}{l}\text { Utian Quality of Life } \\
\text { Scale }\end{array}$ & $\begin{array}{c}\text { Utian } \\
(1972-2018)\end{array}$ & USA & 23 & Five-degree scale & $\begin{array}{l}\text { 1. Work and employment } \\
\text { 2. Lifestyle and health } \\
\text { 3. Emotions } \\
\text { 4. Woman's sexuality }\end{array}$ \\
\hline $\begin{array}{l}\text { Women's Health } \\
\text { Questionnaire }\end{array}$ & Hunter (2000) & UK & $\begin{array}{l}32 \\
23\end{array}$ & Four-degree scale & $\begin{array}{l}\text { 1. Depressive mood } \\
\text { 2. Somatic symptoms } \\
\text { 3. Vasomotor symptoms } \\
\text { 4. Anxiety and fear } \\
\text { 5. Sexuality } \\
\text { 6. Sleep problems } \\
\text { 7. Menstrual symptoms } \\
\text { 8. Memory and concentration } \\
\text { 9. Attractiveness }\end{array}$ \\
\hline
\end{tabular}


Table 2. Graphic design of the Utian Quality of Life Scale questionnaire

\begin{tabular}{lllllll}
\hline Not true of me & Moderately true of me & \multicolumn{3}{l}{ Very true of me } \\
\hline & 1 & 2 & 3 & 4 & 5 \\
\hline 2. I feel challenged by my work & \\
7. I am unhappy with my appearance \\
11. My mood is generally depressed
\end{tabular}

After obtaining empirical data, the researchers performed a factor and item analysis UQOL. The number of items was reduced from 40 to 23. The shortened questionnaire was administered to another research group of 270 women experiencing a period affected by menopause. To determine the questionnaire's reliability (test-retest type), a shortened questionnaire was presented once again to both groups of women during 3 to 7 days. In order to determine the validity of the new shortened questionnaire, women from both groups completed the generic SF-36 questionnaire, allowing a comparison of the results of both questionnaires.

At this stage, the researchers had data on the quality of life of 2 research groups, totalling 597 women. The researchers processed the data by performing an exploratory factor analysis using main component analysis and Promax rotation. The factor analysis identified 4 factors (work and employment; lifestyle and health; emotions; female sexuality), while the items in each factor had a loading value greater than 0.4. The questionnaire domain variability measured by Cronbach $\alpha$ coefficient ranged from 0.643 to 0.839 ; for the questionnaire as a whole it was 0.830 . The validity of the questionnaire (measured by correlation with the results of the generic SF-36 questionnaire) was satisfactory. It ranged from 0.270 to 0.571 , and all relations were statistically significant at $p \leq 0.001$ [21].

Step by step, a 23-item tool (Table 2) was thus created, with items divided into 4 domains: work and employment (items 2, 3, 6, 17, 19, 23), lifestyle and health (items 7 to 10,16, 21, 22), emotional area (items 1,11 to $13,15,20$ ), and female sexuality (items $4,5,14$ ).

The original English version of the UQOL questionnaire was not the only one to be created, but gradually other language versions began to be developed, and the use of the UQOL questionnaire spread to non-English-speaking countries. Chronologically, the following language versions were created:

- German [27],

- Chinese [28, 29],

- Greek [30],

- Portuguese [31],

- Serbian [32, 33],

- Spanish [34],

- Turkish [35],

- Russian [36],
- Indonesian [37],

- Yuruba in Nigeria [38].

The time had come for a Czech version also to be developed.

\section{Czech version of the Utian Quality of Life Scale questionnaire}

\section{Translation and creation of a pilot version}

Before starting the translation, we asked the main author of the UQOL questionnaire, in writing 1 , for his consent to translate the questionnaire into Czech and its use in Czech clinical practice. Having received consent, we proceeded with the translation, respecting the recommended re-translation procedure [39]. We used the original English version of UQOL for translation. Two translators executed the translation independently, then we inspected the various items and their content correctness in the translations. The pilot Czech version of UQOL was created by comparing the various items in the 2 Czech translated versions. Subsequently, we inspected the expert terminology used in the context of the various oestrogen deficiency symptoms. A reverse translation from Czech into English was then carried out by another translator. We compared the English version with the standardized English version of the tool. We were able to state that they corresponded both in terms of content and form. Finally, we submitted the questionnaires to a small group of women of corresponding age $(n=7)$ and asked them to answer the questions and to provide comments, notes, and suggestions for making the questionnaire more comprehensible. Problems emerged in 2 items, in which the respondents showed difficulties with understanding a negated formulation and selecting the corresponding value on the scale of answer number 4-I am not satisfied with my sex life and item and number 7-I am not satisfied with my appearance. Therefore, we added more specific information to these 2 items: If you are not satisfied, mark 5.

The creation of the pilot Czech version took place as part of a broader study in 2014, when its validation and the creation of the final Czech version of UQOL was completed in 2019.

\section{Research group examined}

The group of respondents consisted of 204 women. The selection criteria were as follows: age 49 to 65 years, woman after natural menopause, and the presence of acute oestrogen deficiency symptoms (hot flashes, joint pain, psychological problems, headache, etc.). In terms of treatment, there were 2 groups of

${ }^{1}$ Prof. Wulf H. Utian, MD, PhD, Managing Director of the North American Menopausal Society, based in Ohio, USA. 
women: women prior to hormone replacement therapy (86 women) and women who had been treated for 1 , 3, or 12 months (118 women). Amenorrhoea had been present for at least 12 months in all the women, which corresponds to the definition of menopause by the World Health Organization and International Menopause Society [1]. The women's average age was 54.65 years $(S D=3.48)$. Respondents were clients of gynaecology departments at 4 hospitals in the Czech Republic, where they had been examined due to present oestrogen deficiency symptoms.

\section{Administration of the questionnaire}

The Utian Quality of Life Scale questionnaire was filled in by the respondents voluntarily upon prior written informed consent. The authors of the article contacted respondents who met the selection criteria during the waiting period in the outpatient clinics. The completing time ranged from 10 to 15 minutes. The respondent read the text of each item and expressed her opinion by indicating 1 of the 5 options offered on the assessment scale (1 - fully disagree, 2 - rather disagree, 3 - difficult to decide, 4 - rather agree, 5 - fully agree). The time frame for assessing potential difficulties was in the last month the same as the original English version of the UQOL. The graphic design of the pilot Czech version of UQOL was comparable to the original English version of the questionnaire [21, 23].

\section{Statistical data processing and results}

Using factor analysis, we verified the structure of the Czech version of the UQOL questionnaire. We used confirmatory factor analysis to verify validity. We present results verifying the model implied by the original version of the UQOL questionnaire. However, the results of the factor analysis of the UQOL questionnaire are no longer comparable with the original version.

In the original model, items 2, 3, 6, 17, 19, and 23 represent the Work and Employment domain (UQOL-O), items 7, 8, 9, 10, 16, 21, and 22 represent lifestyle and health domain (UQOL-H), and items 1,11 , $12,13,15$, and 20 represent the emotional area domain (UQOL-E). The remaining items - 4, 5, and 14 - are part of the woman's sexuality domain (UQOL-S). However, the classification of the various items in the Czech version do not correspond to how the individual items of the UQOL questionnaire were grouped in domains in the original version. Table 3 shows the correspondence of items in the pilot Czech version of the UQOL questionnaire to the original domains of the original version based on data obtained in the first phase of the study. Only loadings higher than 0.3 are shown.
Table 3. Utian Quality of Llife Scale items allocation to original domains

\begin{tabular}{|c|c|c|c|c|c|}
\hline \multirow[t]{2}{*}{ Item } & \multicolumn{5}{|c|}{ Factors } \\
\hline & 1 & 2 & 3 & 4 & 5 \\
\hline UQOL01 & 0.41 & 0.39 & 0.33 & & \\
\hline UQOLO2 & 0.47 & & & & -0.34 \\
\hline UQOL03 & 0.76 & & & & \\
\hline UQOL04 & & & & 0.83 & \\
\hline UQOL05 & 0.75 & & & & \\
\hline UQOLO6 & 0.94 & & & & \\
\hline UQOL07 & & & 0.80 & & \\
\hline UQOL08 & & & 0.88 & & \\
\hline UQOL09 & 0.37 & & -0.52 & & \\
\hline UQOL10 & 0.43 & & & & -0.47 \\
\hline UQOL11 & & & & 0.78 & \\
\hline UQOL12 & & & & 0.85 & \\
\hline UQOL13 & & & 0.722 & & \\
\hline UQOL14 & & 0.34 & & & 0.79 \\
\hline UQOL15 & & & & 0.82 & \\
\hline UQOL16 & & & 0.52 & & 0.43 \\
\hline UQOL17 & 0.57 & & & & \\
\hline UQOL18 & & 0.93 & & & \\
\hline UQOL19 & & 0.95 & & & \\
\hline UQOL20 & 0.71 & 0.34 & & & \\
\hline UQOL21 & 0.85 & & & & \\
\hline UQOL22 & 0.64 & & & & \\
\hline UQOL23 & & 0.89 & & & \\
\hline
\end{tabular}

Items allocated to the same various domains in the Czech version are not very similar in content. Basically, the only thing that can be done with the results of the pilot Czech version of UQOL is to sum up all the items to a summary score and interpret the resulting value as a whole.

With respect to such inconsistent results of the research conducted using the original English version and the pilot Czech version of UQOL, we tried to modify the Czech version of UQOL.

However, the classification of the various items in the Czech version does not correspond to how the individual items of the UQOL questionnaire were grouped in domains in the original version. In Table 4 we list the correspondence of items of the pilot Czech version of the UQOL questionnaire to the 5 newly established domains. Only loadings higher than 0.3 are shown.

Items allocated to the same domains in the Czech version are not very similar in content. Basically, the only thing that can be done with the results of the pilot Czech version of UQOL is to sum up all items to a summary score and interpret the resulting value as a sum of all items. 
Table 4. Number of deficiencies (percentage in parenthesis) in micronutrients following sleeve gastrectomy

\begin{tabular}{|c|c|c|c|c|c|c|c|}
\hline $\begin{array}{l}\text { Micronutrient } \\
\text { (normal value range) }\end{array}$ & $\begin{array}{c}\text { Preoperative } \\
n=209(\%)\end{array}$ & $\begin{array}{c}1 \mathrm{yr} \\
n=197(\%)\end{array}$ & $\begin{array}{c}2 \mathrm{yr} \\
n=181(\%)\end{array}$ & $\begin{aligned} & 3 \mathrm{yr} \\
n= & 149(\%)\end{aligned}$ & $\begin{aligned} & 4 \mathrm{yr} \\
n= & 124(\%)\end{aligned}$ & $\begin{aligned} & 5 \mathrm{yr} \\
n= & 103(\%)\end{aligned}$ & $\begin{array}{c}6 \mathrm{yr} \\
n=60(\%)\end{array}$ \\
\hline $\begin{array}{l}\text { Hemoglobin } \\
\text { (male:14-16 pg/ml, } \\
\text { female:12-16 pg/ml) }\end{array}$ & $36(17.2)$ & $\begin{array}{l}54(27.4) \\
p=0.014\end{array}$ & $\begin{array}{l}64(35.4) \\
p<0.001\end{array}$ & $\begin{array}{l}58(38.9) \\
p<0.001\end{array}$ & $\begin{array}{l}51(41.1) \\
p<0.001\end{array}$ & $\begin{array}{l}37(35.9) \\
p<0.001\end{array}$ & $\begin{array}{l}22(36.7) \\
p=0.001\end{array}$ \\
\hline $\begin{array}{l}\text { Iron } \\
(60-180 \mu g / d l)\end{array}$ & $46(22.0)$ & $\begin{array}{l}32(16.2) \\
p=0.141\end{array}$ & $\begin{array}{c}32(17.7) \\
p=0.286\end{array}$ & $\begin{array}{l}40(26.8) \\
p=0.291\end{array}$ & $\begin{array}{l}39(31.5) \\
p=0.056\end{array}$ & $\begin{array}{c}22(21.4) \\
p=0.896\end{array}$ & $\begin{array}{c}15(25) \\
p=0.625\end{array}$ \\
\hline $\begin{array}{l}\text { Ferritin } \\
\text { (male: } 12-300 \mathrm{ng} / \mathrm{dl} \text {, } \\
\text { female: } 12-150 \mathrm{ng} / \mathrm{dl} \text { ) }\end{array}$ & $11(5.3)$ & $\begin{array}{l}42(21.3) \\
p<0.001\end{array}$ & $\begin{array}{l}64(35.4) \\
p<0.001\end{array}$ & $\begin{array}{l}61(40.9) \\
p<0.001\end{array}$ & $\begin{array}{l}55(44.4) \\
p<0.001\end{array}$ & $\begin{array}{l}39(37.9) \\
p<0.001\end{array}$ & $\begin{array}{l}26(43.3) \\
p<0.001\end{array}$ \\
\hline $\begin{array}{l}\text { Folic acid } \\
(5.6-36 \mathrm{ng} / \mathrm{ml})\end{array}$ & $3(1.4)$ & $\begin{array}{c}4(2.0) \\
p=0.645\end{array}$ & $\begin{array}{c}3(1.7) \\
p=0.859\end{array}$ & $\begin{array}{c}1(0.7) \\
p=0.498\end{array}$ & $\begin{array}{c}0(0) \\
p=0.180\end{array}$ & $\begin{array}{c}0(0) \\
p=0.222\end{array}$ & $\begin{array}{c}1(1.7) \\
p=0.896\end{array}$ \\
\hline $\begin{array}{l}\text { Vitamin B12 } \\
(200-900 \mathrm{pg} / \mathrm{dl})\end{array}$ & $8(3.8)$ & $\begin{array}{l}30(15.2) \\
p<0.001\end{array}$ & $\begin{array}{c}18(9.9) \\
p=0.016\end{array}$ & $\begin{array}{c}12(8.1) \\
p=0.086\end{array}$ & $\begin{array}{c}4(3.2) \\
p=0.775\end{array}$ & $\begin{array}{c}10(1.0) \\
p=0.036\end{array}$ & $\begin{array}{c}7(11.7) \\
p=0.019\end{array}$ \\
\hline $\begin{array}{l}\text { Magnesium } \\
(1.7-2.2 \mathrm{mg} / \mathrm{dl})\end{array}$ & $62(29.7)$ & $\begin{array}{c}13(11.7) \\
p<0.001\end{array}$ & $\begin{array}{c}32(17.7) \\
p=0.005\end{array}$ & $\begin{array}{c}26(17.4) \\
p=0.008\end{array}$ & $\begin{array}{c}19(15.3) \\
p=0.003\end{array}$ & $\begin{array}{l}22(21.4) \\
p=0.120\end{array}$ & $\begin{array}{l}12(20.0) \\
p=0.139\end{array}$ \\
\hline $\begin{array}{l}\text { Phosphorus } \\
(2.8-4.5 \mathrm{mg} / \mathrm{dl})\end{array}$ & $11(5.3)$ & $\begin{array}{c}16(8.1) \\
p=0.248\end{array}$ & $\begin{array}{c}8(4.4) \\
p=0.700\end{array}$ & $\begin{array}{c}6(4.0) \\
p=0.588\end{array}$ & $\begin{array}{c}12(9.7) \\
p=0.125\end{array}$ & $\begin{array}{c}5(4.9) \\
p=0.878\end{array}$ & $\begin{array}{c}2(3.0) \\
p=0.539\end{array}$ \\
\hline $\begin{array}{l}\text { Parathormone } \\
(10-55 \mathrm{pg} / \mathrm{ml})\end{array}$ & $6(2.9)$ & $\begin{array}{c}1(0.5) \\
p=0.068\end{array}$ & $\begin{array}{c}1(0.5) \\
p=0.085\end{array}$ & $\begin{array}{c}3(2.0) \\
p=0.609\end{array}$ & $\begin{array}{c}1(0.8) \\
p=0.204\end{array}$ & $\begin{array}{c}1(1.0) \\
p=0.287\end{array}$ & $\begin{array}{c}1(1.7) \\
p=0.606\end{array}$ \\
\hline
\end{tabular}

Based on such inconsistent results of the pilot Czech version of UQOL compared to the original English version of UQOL, we tried to modify the Czech version.

The modification leading to the final version of the Czech version of the UQOL questionnaire mainly consisted of deleting some items (specifically low-loaded items - less than 0.65) and creating new domains depending on how the various items were grouped in new factors. We deleted 5 items from the questionnaire with a factor loading lower than 0.65 . These items assessed the same or a similar problem as other items with a greater loading. The 5 items that we did not include in the final Czech version of UQOL due to their low factor loading are as follows: $1-1$ am able to decide on important matters of my life; 2 - My work is motivating for me; $10-I$ do exercises at least 3 times a week; $14-$ I am satisfied with the frequency of sexual activities with my partner; and 22 - I'm in good shape. In the Czech version of UQOL, these 5 items are substituted with items with higher factor loading.

Based on the performed reduction, the created Czech version contains 18 items, grouped into 4 new domains. We named the various domains according to the focus of the corresponding items included therein. Here is a list of them:

- life satisfaction - items 3, 5, 6, 17, 20, 21,

- open future - items 18, 19, 23,

- overall dissatisfaction - items 7, 8, 9, 13, 16,

- dissatisfaction with sex life - items 4, 11, 12, 15.

To compare the form of the Czech version of the UQOL questionnaire with the original English version, we present a comparison in Table 5.

\section{Reliability of the Czech version}

As for the formal shape of the Czech version of the UQOL questionnaire, no major changes were made to the original version. We differentiated the various items by colour highlighting accordingly, to facilitate orientation in the text. The specification of the time period for which the woman evaluates the symptoms she has experienced "in the last month", remained the same as the original UQOL. The Utian Quality of Life Scale questionnaire includes 18 items divided into 4 new domains.

Table 5. Comparison of the original English version of the Utian Quality of Life Scale questionnaire and its Czech version

\begin{tabular}{|c|c|c|c|c|}
\hline \multicolumn{2}{|c|}{ Original English UQOL version } & \multicolumn{3}{|c|}{ Modified Czech UQOL version } \\
\hline \multicolumn{2}{|l|}{4 domains, 23 items } & \multicolumn{3}{|c|}{4 domains, 18 items } \\
\hline Domain title & Items & Domain title & Original item numbering & Renumbered items \\
\hline Occupational QOL & $2,3,6,17,18,19,23$ & Life satisfaction & $3,5,6,17,20,21$ & $1,3,4,13,16,17$ \\
\hline Health QOL & $7,8,9,10,16,21,22$ & Open future & $18,19,23$ & $14,15,18$ \\
\hline Emotional QOL & $1,11,12,13,15,20$ & Overall dissatisfaction & $7,8,9,13,16$ & $5,6,7,10,12$ \\
\hline Sexual QOL & $4,5,14$ & Dissatisfaction with sex life & $4,11,12,15$ & $2,8,9,11$ \\
\hline
\end{tabular}

UQOL - Utian Quality of Life Scale, QOL - quality of life 
The original version of the UQOL questionnaire uses coloured questionnaire form for evaluating a completed questionnaire. Individual domain scores and overall scores are evaluated. The given woman's quality of life is assessed based on the resulting score. We created the same model containing new domains for the Czech final version of the tool. The overall score is between 18 and 90 points. The higher the score in the various domains and the total score, the more severe the given woman's issues and the more severely affected can be her quality of life.

From the perspective of internal consistency, we focused on Cronbach's $\alpha$, which is 0.79 for the Czech version of UQOL. Utian et al. [21] reported the Cronbach $\alpha$ value of the original UQOL version to be 0.83 , suggesting a relatively high internal consistency.

\section{Validity of Czech version}

For the creation of Czech version of the specific questionnaire, it is important to determine the extent to which the questionnaire measures the same construct, being the quality of life of women in the period affected by menopause, i.e. to find out how valid it is. Concurrent validity can be ascertained by correlation analysis.

Correlations between the Czech version of the UQOL questionnaire and the MRS administered to the same group of women are medium to high, ranging from -0.338 to -0.648 . Correlations between the Czech version of the UQOL questionnaire and some items of the generic SF-36 questionnaire are also relatively high. Because SF-36 is composed of different (i.e. general) domains of quality of life, very high correlations cannot be expected. Nevertheless, some UQOL domains correlate highly with SF-36 items (SF-36 item 3, sum of items $6-8$, and part of item 9 - positive emotions with the lifestyle and health domain).

\section{Discussion}

The fundamental difference between the Czech version of UQOL and the original English version of UQOL is in the factor structure of the questionnaire: Czech items are grouped differently for the Czech women's group than English items in English-speaking women's research groups. It is not easy to interpret this finding. On the one hand, the structure of the UQOL questionnaire appears to have certain general features (the same 4-factor structure is referred to in the literature in other language versions - Chinese, Turkish, Spanish, Greek). On the other hand, for example, the Serbian version came to a 6-factor solution, adding 2 new factors to the original 4 factors (physical fitness, professional recognition). A possible explanation may be the experts' warning that menopause is not just a bio-psychological issue but a complex bio-psycho-socio-cultural matter [15]. Czech women seem to understand and experience their problems a little differently than, for example, American women. A similar problem was encountered by Mares et al. [40] in Czech seniors while creating the Czech version of the OPQOL-35 questionnaire (older people's quality of life questionnaire), determining the perception and evaluation of the quality of life among seniors. Also in this case, the Czech structure of the questionnaire differed from the original questionnaire, which was standardized for a British research group of seniors.

The Utian Quality of Life Scale questionnaire is completed by the women themselves, thus meeting the "golden rule" of all quality-of-life research, stating that the primary source should be data from the clients themselves, not from family members or professionals caring for them. However, this requirement raises 3 methodological problems.

The first are the individual particularities of the client, affecting her perception, experience, and evaluation of what she is experiencing. This problem is typically more pronounced in the period affected by menopause, when a woman undergoes hormonal, somatic, family, social, and occupational transformations and her difficulties may potentiate each other.

The second problem is in the woman's level of willingness to cooperate and to truthfully answer to all items in the questionnaire. The respondent may downplay or exaggerate some of difficulties and, conversely, conceal or negate others. This was also shown in our study that some women refused to comment on problems in the sex domain because they considered them too intimate. This implies that the information value of the data may be biased in various ways in different women.

The third problem is women's culturally influenced attitude to menopause. A review study [41] found that women with significantly negative attitudes to menopause report considerably more annoying symptoms during the climacteric period than women who accept this transition. However, the direction of causality remains unknown. Does a greater number of experienced unpleasant symptoms result in more negative attitudes to the climacteric, or are negative attitudes the primary factor making the woman more sensitive and therefore causing her to experience her problems more intensively? In other words, is the negative attitude a result of difficulties or does the woman's negative attitude towards menopause play a primary role?

The wider context of menopause mentioned above may also be involved: not only does the woman's attitude to menopause play a role, but also the social dimension and the attitude of the relevant culture to menopause. Research suggests that the western medicalisation hypothesis may apply to Euro-Atlantic culture. 


\section{Conclusions}

Natural and multidimensional processes are being reduced to a purely medical problems that need to be treated as a disease. This attitude is adopted by the media and pharmaceutical companies, and the image of the natural process is distorted. Women in western countries then perceive and experience menopause as a disease. Their attitude to it is then much more negative than in the case of women from other cultures in which menopause is considered a natural part of a woman's life cycle [41].

The menopause is a current topic across cultures and healthcare systems. The Czech version of UQOL can be the basis for the creation of other culturally adapted language versions, and it can also be a guide for changing the original English version.

\section{Acknowledgements}

From the perspective of possible conflict of interests, we did not find any circumstances that would threaten the fundamental publication principles. This study was approved by the ethics committees of the workplaces from which data were collected for research.

The present publication was elaborated within a broader study, and all authors collaborated on the creation of this publication. The research was funded from the resources of the first author's workplace.

A prerequisite for participation in the broader study, which also included the elaboration of a Czech standardized version of the UQOL, was the client's informed consent to participate in the study. At the same time, respondents received an introduction letter with basic information on the study and its purpose.

Before the start of the study the authors of the original version of UQOL were contacted and asked for consent to use the English version of the questionnaire, its potential publication in scientific publications, and the creation of a Czech version of UQOL. We obtained this consent in writing with the precondition that the questionnaire authors would be informed about the results of our study.

\section{Disclosure}

The authors report no conflict of interest.

\section{References}

1. Utian WH. The International Menopause Society menopause-related terminology definitions. Climacteric 1999; 2: 284-286.

2. Kolarik D, Halaska M, Feyereisl J. Repetitorium gynecology. [Repetitorium gynekologie.] $1^{\text {st }}$ issue Prague: Maxdorf 2008.

3. Franke P. Gynecological and obstetric clinical images of the disease. [Gynekologické a porodnické klinické obrazy nemoci.] Psychosom 2010; 8: 10-18.
4. Cheng MH, Lee SJ, Wang SJ, et al. Does menopausal transition affect the quality of life? A longitudinal study of middle-aged women in Kinmen. Menopause 2007; 14: 885-890.

5. Kumari $M$, Stafford $M$, Marmot $M$. The menopausal transition was associated in a prospective study with decreased health functioning in women who report menopausal symptoms. J Clin Epidemiol 2005; 58: 719-727

6. Mishra GD, Brown WJ, Dobson AJ. Physical and mental health: changes during menopause transition. Qual Life Res 2003; 12: 405-412.

7. Waheed K, Khanum A, Butt A, et al. Quality of life after menopause in pakistani women. Gynecol Obstet (Sunnyvale) 2016; 6: 367.

8. Rapley M. Quality of life research. Sage Publications, London 2003.

9. Centers for disease control and prevention. Measuring health days. Atlanta: CDC. 2000. https://www.cdc.gov/hrqol/pdfs/mhd.pdf.

10. Brown J, Bowling A, Flynn T. Models of quality of life: a taxonomy, overview and systematic review of literature. In Proceedings of European Forum on Population Ageing Research. Sheffield: Department of Sociological Studies. http://www.ageingresearch.group.shef.ac.uk/ pdf/qol_ review_no_tables.pdf, 2016.

11. Zöllner ZF, Acquadro C, Schaefer M. Literature review of instruments to assess health-related quality of life during and after menopause. Qual Life Res 2005; 14: 309-327.

12. Wender MCO, de Oliveira PP. Quality of life. In: Farage M, Miller K, Fugate Woods N, et at., eds. Skin, mucosa and menopause. Springer: Berlin 2015.

13. Palacios S, Ferrer-Barriendos J, Parrilla JJ, et al. Design of a new specific quality of life scale for menopause in Spanish language, the Cervantes Scale. Climateric 2002; 5 (Supplement 1): 159.

14. Greene JG. Constructing a standard climacteric scale. Maturitas 1998; 29: 25-31.

15. Hunter MS, Rendall M. Bio-psycho-socio-cultural perspectives on menopause. Best Pract Res Clin Obstet Gynaecol 2007; 21: 261-274.

16. Jacobs P, Hyland ME, Ley A. Self-rated menopausal status and quality of life in women aged 40-63 years. Br J Health Psychol 2000; 5: 395-411.

17. Heinemann K, Ruebig A, Potthoff P, et al. The Menopause Rating Scale [MRS] scale: a methodological review. Health Qual Life Outcomes 2004; 2: 45.

18. Hilditch JR, Lewis J, Peter A, et al. A menopause-specific quality of life questionnaire: development and psychometric properties. Maturitas 1996; 24: 161-175

19. Perz JM. Development of the menopause symptom list: a factor analytic study of menopause associated symptoms. Women Health 1997; 25: 53-69.

20. Le Floch JP, Colau JC, Zartarian M. Validation d'une méthode d'evaluation de la qualité de vie en menopause. Gynecol Obstet 1994; 2: 179-188.

21. Utian WH, Janata JW, Kingsberg SA, et al. The Utian Quality of Life [UQOL] Scale: development and validation of an instrument to quantify quality of life through and beyond menopause. Menopause 2002; 9: 402-410.

22. Hunter MS. The Women's Health Questionnaire [WHQ]: the development, standardization and application of a measure of mid-aged women's emotional and physical health. Qual Life Res 2000; 9 (Supplement 1): 733-738.

23. Moravcova, M. Rating Health-Related Quality of Life after Menopause [Hodnocení kvality života žen po menopauze. Doctoral dissertation.] Faculty of Medicine in Hradec Kralove, Hradec Králove: Charles 2014.

24. Moravcova M, Hola J. Utilizing the Menopause Rating Scale questionnaire in electronic form for evaluating the quality of life in postmenopausal women. Kontakt 2017; e12-e16. http://www.corptransinc.com/ Sites/GreeneClimacteric-Scale/home.aspx. Accessed February 25, 2019.

25. Gawlicki M. Green Climacteric Scale. http://www.corptransinc.com/ Sites/GreeneClimactericScale/home.aspx. Accessed February 25, 2019.

26. Utian WH. The mental tonic effect of estrogens administered to oophorectomized females. S Afr Med J 1972; 46: 1079-1082.

27. Hermann PG, Schneider MD. The quality of life in the postmenopausal woman. Best Pract Res Clin Obstet Gynaecol 2002; 16: 395-409.

28. Chen PL, Chao HT, Chou KR, et al. The Chinese Utian Quality of Life Scale for women around menopause: translation and psychometric testing. Menopause 2012; 19: 438-447.

29. Li S, Ho SC, Sham A. Relationship between menopause status, attitude toward menopause, and quality of life in Chinese midlife women in Hong Kong. Menopause 2016; 23: 67-73. 
30. Giannouli P, Zervas I, Armeni E, et al. Determinants of quality of life in Greek middle-age women: a population survey. Maturitas 2012; 71: 154-161.

31. Lisboa LL, Utian WH, da Fonseca-Filho GG. Translation, adaptation and validation of the Brazilian version of the Utian Quality of Life for evaluation of quality of life in the climacteric. Rev Bras Ginecol Obstet 2015; 37: 520-525.

32. Dotlic J, Pimenta F, Kovacevic N, et al. Menopausal transition in Southern Europe: comparative study of women in Serbia and Portugal. Menopause 2017; 24: 1236-1245.

33. Dotlic J, Gazibara T, Rancic B, et al. Translation and validation of the Utian Quality of Life Scale in Serbian peri- and postmenopausal women. Menopause 2015; 22: 984-992.

34. Cortes-Bonilla M, Alonso-Campero R, Bernardo-Escudero R, et al. Improvement of quality of life and menopausal symptoms in climacteric women treated with low-dose monthly parenteral formulations of nonpolymeric microspheres of $17 \beta$-estradiol/progesterone. Gynecol Endocrinol 2016; 32: 831-834.

35. Abay H, Kaplan S. Validation and reliability of the Turkish Utian Quality of-Life Scale in postmenopausal women. Menopause 2016; 23: 425-432.

36. Kirichenko TV, Myasoedova VA, Orekhova VA, et al. Phytoestrogen rich natural preparation for treatment of climacteric syndrome and atherosclerosis prevention in perimenopausal women. Phytother Res 2017; 31: 1209-1214.

37. Wulandari P, Soeroso Y, Maharani DA, et al. Validity and reliability of a modified Utian Quality of Life Scale for Indonesian postmenopausal women. J Int Dent Med Res 2018; 11: 231-237.

38. Obalowu A, Odeigah $\mathrm{O}$, Alabi $\mathrm{M}$, et al. Adaptation and translation of the menopause-specific Utian Quality of Life [UQOL] scale to Yoruba language using middle-aged women attending a clinic in Nigeria. Menopause 2019; 26: 311-316.

39. Acquadro C, Jambon B, Ellis D, et al. Languages and translation issues. In: Quality of life and pharmacoeconomics in clinical trial. $2^{\text {nd }}$ ed. Spilker B (ed.), Philadelphia: Lippincott-Raven 1996.

40. Mares J, Cigler H, Vachková E. Czech version of OPQOL-35 questionnaire: the evaluation of the psychometric properties. Health Qual Life Outcomes 2016; 14: 1-13.

41. Ayers B, Forshaw M, Hunter MS. The impact of attitudes towards the menopause on women's symptom experience: a systematic review. Maturitas 2010; 65: 28-36. 